Anais da Academia Brasileira de Ciências (2012) 84(1): 79-93

(Annals of the Brazilian Academy of Sciences)

Printed version ISSN 0001-3765 / Online version ISSN 1678-2690

www.scielo.br/aabc

\title{
Redescription of Tijubina pontei, an Early Cretaceous lizard (Reptilia; Squamata) from the Crato Formation of Brazil
}

\author{
TIAGO R. SIMÕES \\ Setor de Paleovertebrados, Departamento de Geologia e Paleontolgia, \\ Museu Nacional, Universidade Federal do Rio de Janeiro, \\ Quinta da Boa Vista, s/n, 20940-040 Rio de Janeiro, RJ, Brasil. \\ Manuscript received on August 19, 2011; accepted for publication on November 9, 2011
}

\begin{abstract}
The record of Gondwanan Mesozoic lizards is very poor. Among the few species described for this region there is Tijubina pontei, an Early Cretaceous lizard from the Crato Formation (late Aptian) of northeast Brazil. Its description is very brief and lacks most of its diagnostic characters and clear delimitation from other lizard species. Here, a full redescription of the holotype is provided. T. pontei is demonstrated to be a valid species and a new diagnosis is provided with reference to Olindalacerta brasiliensis, a contemporary species of the Crato Formation. It lacks the posteroventral and posterodorsal processes of the dentary; the tibial/fibular length equals the femoral length and its posterior dentary teeth are robust, cylindrically based, unsculptured and bear no cuspids. The systematic position of $T$. pontei still needs further clarification, but preliminary analyses indicate that it lies in a rather basal position among the Squamata, similarly to $O$. brasiliensis.
\end{abstract}

Key words: Brazil, Crato Formation, fossil lizard, Lower Cretaceous, Tijubina pontei.

\section{INTRODUCTION}

Lizard remains from the Mesozoic of Gondwanan derived continents are extremely rare. There is a proportionally higher number of snakes relative to lizards taxa in these regions and with a pattern opposite to that seen in Laurasia, where fossil lizards are much more common than fossil snakes (Krause .2003). Among the few taxa described, there are the species Tikiguana estesi Datta \& Ray 2006, from the Late Triassic (Carnian) of India; Bharatagama rebbanensis Evans, Prasad \& Manhas 2002, from the Lower-Middle Jurassic of India; Paramacellodus

Correspondence to: Tiago Simões

E-mail: tsimoes@mn.ufrj.br marocensis Richter 1994 and Tarratosaurus anoualensis Broschinski \& Sigogneau-Russell 1996 from the Early Cretaceous (Berriasian) of Morocco; Konkasaurus mahalana Krause, Evans \& Gao 2003 from the Late Cretaceous (Maastrichtian) of Madagascar; Pristiguana brasiliensis Estes \& Price 1973 from the Late Cretaceous of southeast Brazil; Brasiliguana prudentis Nava \& Martinelli 2011 from the Late Cretaceous (Turonian-Santonian) of southeast Brazil; Olindalacerta brasiliensis Evans \& Yabumoto 1998 and Tijubina pontei Bonfim-Júnior \& Marques 1997 from the Late Cretaceous (Aptian-Albian) of the Crato Formation of northeast Brazil. Whether this distribution 
difference is real or represents differential research efforts between areas in the northern and the southern hemisphere is still unknown (Evans 2003).

To this day, the only valid species for South America are the four above ones from Brazil. The two Early Cretaceous taxa are significantly better preserved, both with cranial and numerous postcranial elements, whereas the Late Cretaceous ones are represented almost exclusively by cranial fragments. Phylogenetically, Olindalacerta was interpreted as a sister group to Scleroglossa, clustering close to Eichstaettisaurus (Evans \& Yabumoto 1998), a basal squamate from the Late Jurassic and Early Cretaceous of Europe. Tijubina pontei was originally described as a teiid (BonfimJúnior and Marques 1997), then as a basal Squamate (Bonfim-Júnior and Avilla 2002) and even as a Rhyncocephalia (Martill and Frey 1998). It is a wellpreserved specimen, but $T$. pontei material remains largely undescribed (Evans 2003); therefore, a redescription is necessary. This may allow Tijubina to have a better supported systematic positioning among the squamates and provide more data to future phylogenetic analyses, thus contributing to an advance in the understanding of the Cretaceous lizard fauna in Brazil.

Here a full redescription of Tijubina pontei is presented, along with a reinterpretation of its systematic position, based on new data from its holotype housed at the Museu de Paleontologia de Santana do Cariri (MPSC-V 010), which is the only currently available material attributed to this species.

\section{GEOLOGICAL BACKGROUND}

The Araripe Basin in northeast Brazil can be divided into two main sub-basins: the West or Feitoria subbasin and the East or Feira Nova sub-basin (Viana and Neumann 2002, Martill et al. 2007). It contains the Santana Group where the Arajara, Romualdo, Ipubi, Crato and Rio da Batateira formations crop out, from top to base (Neumann and Cabrera 1999, Valença et al. 2003). The Romualdo and Crato formations are among the most fossiliferous and important fossil deposits in Brazil and are considered world quality lagerstätten (Maisey 1993, Kellner and Campos 1999). The holotype of Tijubina pontei comes from the Crato Formation, which is known to have produced several thousand specimens of fishes, plants and arthropods, including insects (Martins-Neto 2002, Santos et al. 2011), crustaceans (Martins-Neto 1987) and chelicerates (Campos 1986). Among tetrapods, there were found turtles (Oliveira and Kellner 2007), crocodilians (Kellner 1998), pterosaurs (Frey and Martill 1994, Campos and Kellner 1997), anurans (Leal and Brito 2006, Báez et al. 2009), fossil feathers (Kellner et al. 1994, Sayão et al. 2011) and the two published species of lizards mentioned above. The Crato Formation consists mostly of thin laminated limestones with variable clay content and dark-coloured calciferous shales (Valença et al. 2003). This represents a carbonatic lacustrine environment and is late Aptian to Aptian/Albian in age (Maisey 1991, Neumann and Cabrera 2002, Valença et al. 2003), despite diverging opinions on its precise dating (see Maisey 1991 for further details). This ancient lake was formed due to tension stresses on the South American plate during the rift phase at the opening of the Atlantic Ocean. It was located in an arid region and was one of the last points of contact between South America and Africa before their full separation by the Aptian/Albian transition (Maisey 1993).

\section{MATERIALS AND METHODS}

Considering the small size of the specimen, measurements were done digitally utilizing high resolution pictures, which provide greater precision. The proportion between fore and hind limbs has been calculated based on the length of the propodials plus the epipodials, excluding the autopodium. This is necessary so the digital formula, which is an 
independent character, does not affect the fore/hind limbs length ratio. Furthermore, the propodial and epipodial lengths make the biggest contribution to the limbs total length.

The published phylogenetic analyses of the Squamata considered for the systematic positioning of $T$. pontei within this group were chosen based on two main criteria. The first one is to include an extensive taxonomic sampling throughout the Squamata, and the second, to have an osteologically based diagnoses for the major monophyletic groups that were found. These are the works of Estes et al. (1988), Lee (1998) and Conrad (2008).

Abbreviations used: acf, anterior coracoid fenestra; ans, annulated scales; ante, anterior dentary tooth/teeth; bd, basal portion of dentary; c, coronoid; cbr I, ceratobranchials I; cl, clavicle; cr, carpal rows; d, dentary; dd, dorsal portion of dentary; dss, dentary-suragular suture; ec, ectopterygoid; epco, epicoracoid; I - IV, first to fourth digits; fe, femur; fi, fibula; hu, humerus; icl, interclavicle; il, ilium; ims, intramandibular septum; is, ischium; j, jugal; m, maxilla; mc, metacarpals; mecf, Meckelian fossa (open canal); mt II - IV, second to fourth metatarsals; mt V, fifth metatarsal; mte, maxillary tooth/teeth; obfo, obturator foramen; paa, prearticular-articular complex; pcr, primary coracoid ray; pdte, posterior dentary teeth; prst, presternum; ptg, pterygoid; pu, pubis; pvcp, posteroventral coronoid process; ra, radius; rap, retroarticular process; rhs, rhomboid scales; ri, ribs; san, surangular; sca, scapula; scasrf, sternal ribs faces; scfo, supracoracoidal foramen; scof, scapulacoracoid fenestra; sds, subdental shelf; stf, sternal fontanelle; sy, symphysial region of the pelvis; thf, thyroid fenestra; ti, tibia; ul, ulna.

\section{Systematic Paleontology}

Squamata Oppel, 1811

Scleroglossa Estes et al., 1988

Evansauria Conrad 2008

Genus Tijubina Bonfim-Júnior \& Marques 1997
Type species: Tijubina pontei Bonfim-Júnior \& Marques 1997, by monotypy.

Diagnosis: as for species

Tijubina pontei Bonfim-Júnior \& Marques 1997

Revised and extended diagnosis: Tijubina pontei differs from other Cretaceous squamates by the following combination of characters: surangular and coronoid processes of dentary absent; tall facial process of maxilla; jugal slender with pointed ends, curved and with partial overlap with the maxilla anteromedially; ectopterygoid limited to posterolateral margin of suborbital fenestra, not extending further anteriorly; meckelian canal open medially; splenial absent or much reduced; deeply implanted cylindrically based pleurodont teeth; anteriormost teeth of the mandibles slender, unicuspidate and unsculptured; very robust posterior dentary and maxillary teeth, with a sharply pointed apical region that lacks any processes or ornamentation; cylindrical base of posterior dentary teeth separated from their apex by a small increase in the tooth's width (a shoulder region); three sternal ribs; posterior coracoid fenestra absent; interclavicle cruciform with distinct anterior process and longitudinal crest on dorsal surface; clavicles angulated at proximal articulatory end with the interclavicle; metacarpal 4 longer than metacarpals 1 and 2 , equal or subequal in length to metacarpal 3; posterior limbs much longer than anterior ones; tibial and fibular length equal or subequal to the femur; metatarsals elongated; feet extremely elongated; ventral small rhomboid scales on the neck, large rhomboid scales on the trunk and annulated ones on the ventral side of the entire caudal region.

Holotype: The holotype and only specimen currently available for analysis is MPSC-V 010 (Museu de Paleontologia de Santana do Cariri) and consists of a few skull elements with associated mandibles, an almost fully preserved pectoral girdle 
and forelimbs, few thoracic ribs, part of the pelvic girdle and the distal portion of the hind limbs.

Type locality: Nova Olinda, Ceará State, Brazil.

Stratigraphy and age: Araripe Basin, Crato Formation konservat laggerstätten (Brazil); Lower Cretaceous - late Aptian to Aptian /Albian.

Remarks: According to Bonfim-Júnior and Marques (1997) the holotype was collected at a limestone quarry at the city of Nova Olinda close to Santana do Cariri, in the state of Ceará, northeastern Brazil (07 6' 44"S; 39 41' 45"W)'. A second specimen, referred as a counterpart of the holotype, was mentioned by Martill et al. (2007, p. 461), but its location is unknown.

\section{DESCRIPTION}

The holotype of Tijubina pontei is a skeletally immature, small sized terrestrial lizard with $46.64 \mathrm{~mm}$ in length (snout-pelvis). It is preserved in dorsal view and is slightly tilted to its right side, with most of its elements in articulation (Fig. 1a). Impressions of some of the missing bones are seen in low relief on the soft calcareous matrix around it. Also, there are small patches of skin impressions posterior to the head.

Osteological preserved elements include - Skull: maxilla (right); jugal (right); both ectopterygoids; pterygoid (left); both ceratobranchials. Mandibles: both dentaries; coronoid (right); both surangulars; prearticulararticular (right). Dentition: dentary teeth (anterior and posterior); maxillary teeth. Axial skeleton: sternal ribs (articulatory faces on presternum); thoraxic ribs. Pectoral girdle: presternum; both epicoracoids; both coracoids; both scapulae; interclavicle; both clavicles. Forelimbs: both humeri; radio and ulna (right and partially on left); radiale and ulnare (right); all distal carpals (right); metacarpals I - IV (right and left); phalanges (right and left). Pelvic girdle: ilium (right); both Ischia; pubes (right). Hind limbs: femur (right); tibia and fibula (right); astragalum and calcaneum (right); metatarsals II - V; phalanges (right and left).

CRANIUM

The skull of the specimen has few preserved elements in comparison with the mandibles for instance and is mostly seen in dorsal aspect. On the right side, the maxilla is the anteriormost cranial element preserved and is slightly tilted laterally, exhibiting its roughly triangular facial process in dorsomedial view (Fig. 1b and 1c). The maxillary shelf is shallow and bears four countable teeth. The teeth, along with the remaining posterior process of the maxilla, partially penetrate beneath the right jugal, indicating that the anterior end of the jugal might have excluded the maxilla from the orbital margin. The jugal tapers the maxilla dorsolaterally, and is slightly curved ventrally. It would have formed the ventral, anteroventral and posteroventral margins of the orbit, but not reaching its dorsal half neither anteriorly nor posteriorly. Thus, the postorbital and postfrontal must have formed the major portion of the postorbital margin above the jugal.

The ectopterygoid can be identified based on its morphology and topology in the skull. It touches the jugal anteromedially and is limited further anteriorly by the maxilla. It is flattened dorsoventrally and its posterior end projects medially into the skull, where it would have met the pterygoid flange (Fig. 2a). On the left side of the skull, part of the other ectopterygoid is preserved at the same relative position, but slightly inclined medially, indicating this might represent the original position of these bones. Posteromedially to the left ectopterygoid, part of the anterior portion of the pterygoid is visible, providing, along with the ectopterygoid, a general aspect of the posterolateral margin of the left suborbital fenestra. The pterygoid projects posterolaterally via its quadrate process for more than half of its length (Fig. 1b and 1c). 


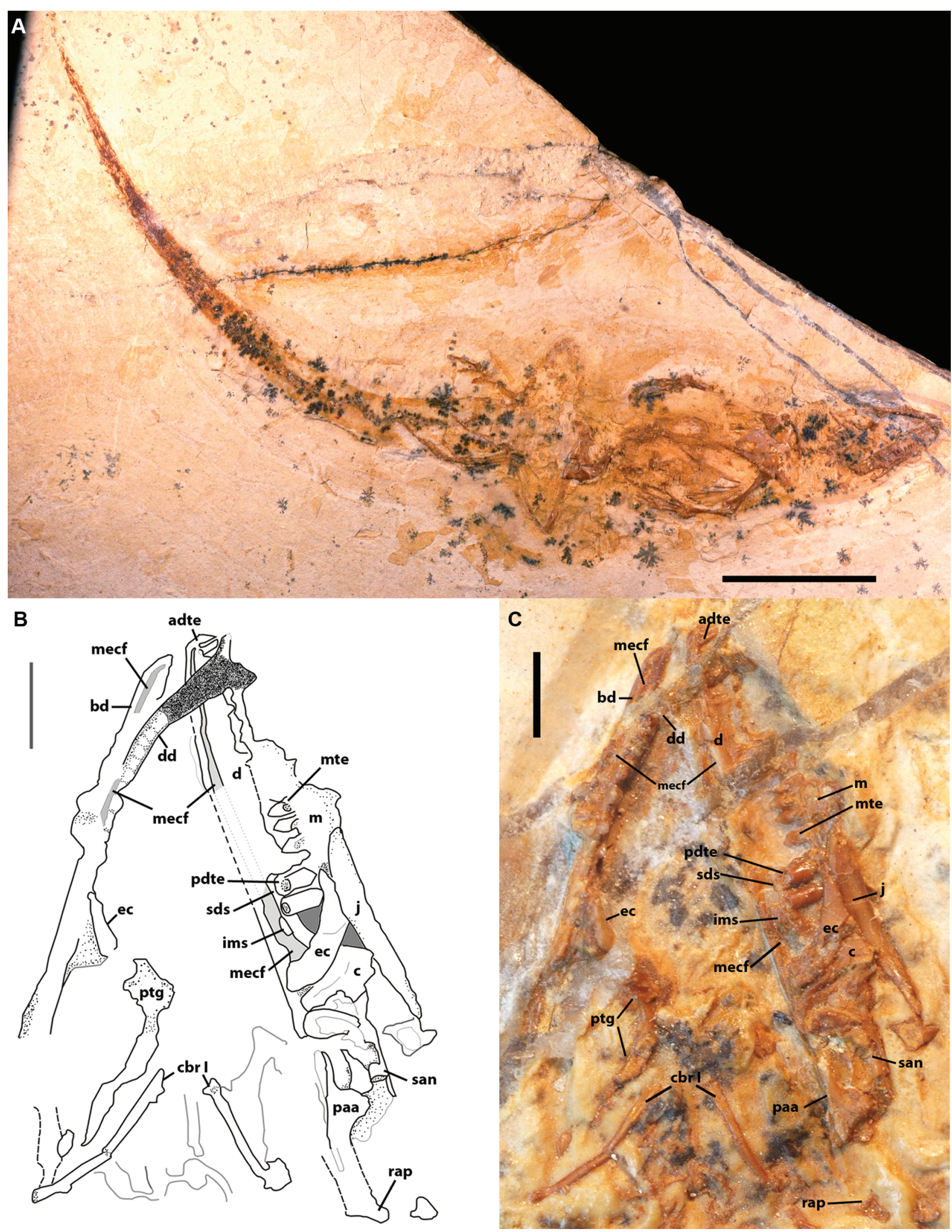

Fig. 1 - Tijubina pontei holotype MPSC-V 010. A, Calcarious slab containing the holotype in dorsal aspect. Scale $=20 \mathrm{~mm}$. B \& $\mathbf{C}$, Drawing and picture (respectively) of the head in dorsal view. Both scales $=2 \mathrm{~mm}$. 


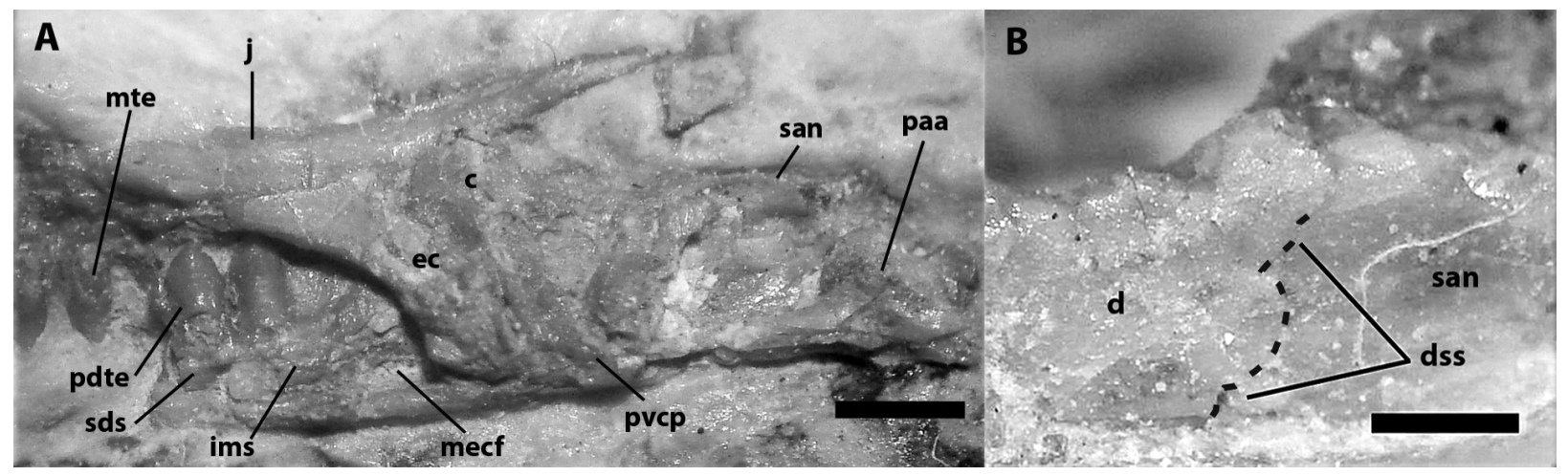

Fig 2. A, Enlarged view of the posteromedial face of the right mandible and the few remaining cranial elements preserved over it. Scale $=1 \mathrm{~mm}$. B, Left mandible of MPSC-V 010 in dorsolateral view. Enlarged vision of the suture line region between the dentary and surangular in lateral view. Scale $=0.5 \mathrm{~mm}$.

The braincase is extremely fragmentary and unfortunately cannot be properly analysed. The hyoid apparatus lies at the level of the braincase and is represented by the first pair of ceratobranchials. They are a couple of stout rod-like structures, the anterior ends of which lie close to the pterygoid and project posterolaterally at a smooth angle until about the same level of the posterior extremity of the braincase and left mandible.

\section{MANDIBLES}

Both mandibles are well preserved, the left one is seen dorsally and the right one medially from above, as it was tilted laterally and is pressing against the elements of the upper jaw. On the right mandible, the dentary makes up the mandible's whole anterior and medial portions, with an open Meckelian canal extending through its whole visible extension from the symphisis to the level of the coronoid. It is broken ventrally at the level of the facial process of the maxilla, allowing a partial glance into its transverse section and the Meckelian canal. This open canal, along with no preserved splenial at the posteromedial end of the dentary, may indicate that this jaw bone was absent in $T$. pontei. The absence of a splenial articulatory surface on the medial side of the dentary, which is usually present on the ascending portion of the posterior dentary, reinforces this statement. However, if the splenial was much reduced, it might not have been preserved and the articulatory surface for it could not be visible due to the posterior overlap of the ectopterygoid over the mandible. Therefore, the splenial was either absent or was much reduced in this species.

The right dentary bears a shallow subdental shelf with two preserved teeth in loci, facing against the point of contact between the maxilla and the ectopterygoid (Fig. 2a). Also, these teeth lie just anteriorly to the ascending posterior portion of the subdental shelf, indicating that these are among the last teeth of the lower jaw. Ventrally to it, a small ventral process of the intramandibular septum is visible. After this point, the dentary is overlapped by the right ectopterygoid, hiding the face of contact on the dentary for the coronoid and, maybe, the anterior portion of the surangular.

The coronoid is seen behind the region of contact with the ectopterygoid, with its distinct dorsal process, part of the posterior process and an extensive posteroventral process that descends to the level of the ventral jaw margin. A separate element lies posterior to the coronoid and may represent part of the surangular by its position, but its preservational condition prevents an assured identification. The posteriormost preserved bone in 
the right mandible is a short element with a stout structure at its base, which would have extended posteriorly in the jaw. From this and its topology, it might be the anterior portion of the prearticulararticular complex. The posterior end of the right mandible is missing, making it unfeasible to reconstruct it properly. Yet, we were able to see the impression of these bones on the matrix and determine the jaw's posterior limit, which is useful for the measurements of the head.

The angular could not be detected, but this might be due to the bad preservation of the ventral margin of the lower jaw, especially at the level of the overlap between the ectopterygoid and the dentary.

The left mandible is particularly difficult to observe as it is partially hidden on the calcareous matrix and its medial side is densely crystallized, making most of it only visible on dorsolateral aspect. Nevertheless, it shows in its anteriormost end the sulcus of the open Meckelian canal of the dentary, which is somewhat easier to observe than on the equivalent position at the right dentary. The teeth bearing (dorsal) portion of the left dentary was detached from its base and lies medial to it, curving towards the right mandible. Laterally, there can be seen regularly spaced and roughly triangular elements above this dorsal portion, which might be the apical portion of the highly crystallized teeth. The posterior end of the left mandible is visible laterally, something unfeasible on the right one. At this point, an irregular dorsoventrally running suture demarcates the limit between the dentary and the surangular, just anterior to the level where the left ectopterygoid touches the lower jaw (Fig. $2 b)$. There is no distinct coronoid (posterodorsal) or surangular (posteroventral) processes of the dentary forming a surangular notch on lateral aspect. The surangular dominates the postero-lateral face of the preserved mandible and extends posteriorly until its broken margin. The prearticular-articular region of the left mandible is not preserved. However, as on the right one, its posterior extremity is visible in low relief on the matrix and stands approximately at the same level as the posteriormost end of its right counterpart.

\section{DENTITION}

Teeth are present in the right maxilla and dentary. The specimen has heterodont dentition with the first teeth of the mandible being slender, slightly conical, unicuspidate and unsculptured. Posteriorly, but still at the anterior portion of the dentary, the insertion area of one tooth is exposed, evidencing that teeth were deeply implanted and pleurodont. The posterior dentary teeth are morphologically similar to each other as well as to the maxillary ones. They are much thicker, but not taller, than the anteriormost teeth on the lower jaw. They are extremely robust with cylindrical bases, also unsculptured and bear no cuspids. Their apical region is sharply pointed and represents one third of its height, being separated from their basal portion by a slight increase in its width - a shoulder region (Fig. 2a). The crista dorsalis is not visible in the posterior half of the dentary, making it difficult to determine if the teeth were well exposed above it or only their apices. Anteriorly to the level of the facial process of the maxilla there are broken teeth with only their cross section exposed at the dentary. They are circular and intermediate in diameter between the anteriormost teeth and the posterior dentary and maxillary teeth.

\section{AXIAL SKELETON}

Despite the general good state of preservation of the specimen, no vertebrae are entirely preserved. Some impressions of cervical and caudal vertebrae are visible, but they do not provide sufficient information for vertebral count or morphological analysis. 
There are three facets for the articulation with the sternal ribs on the left side of the presternum, but the ribs themselves are lacking. In the trunk, only one rib is preserved at the posterior left side of the body. On the right side, however, there are the distal portions of five ribs seen serially arranged, followed by the impression of other two. They are laterally compressed and lightly curved, but their distal ends face posteriorly, indicating that they must have been highly angled proximally.

\section{PECTORAL Girdle}

The presternum is the only preserved portion of the sternal plate. It has a general rhomboid shape in dorsal view and is mostly cartilaginous. It bears three articular facets for the sternal ribs on the left side projecting posterolaterally, but lacks them on its right side (Fig. 3a). The sternal fontanelle is significantly open and dominates the posterocentral half of this element, which generally indicates ontogenetic immaturity (Russell and Bauer 2008). The coracosternal suture is demarcated by a thick anterolateral rim, which separates the presternum from the epicoracoid cartilage anteriorly. The epicoracoid cartilage can be distinguished from the sternal one as it slots into the presternum anterior groove. The epicoracoid expands anteriorly up to the level of the lateral process of the interclavicle. However, it was not as well preserved as the presternum, presenting fragmented patches of cartilage that allow for the view of the interclavicle's posterior shaft ventrally (Fig. 3a).

Both scapulae and coracoids are unfused, which is another indicator of the specimen immaturity. They are preserved close to the articulating point with the humerus and are separated from each other medially by the epicoracoid cartilage. The coracoids lie posteromedially in relation to the scapulae and have the supracoracoid foramen characteristically standing between the glenoid face and the anterior coracoid fenestra. Posterior to this fenestra there is a small aperture with irregular and crenulated margins in the position expected for the posterior coracoid fenestra. Also, it is not present in the left coracoid. All these indicate that this is a broken portion of the posterior region of the right coracoid and that the posterior fenestra is absent in the coracoids of T. pontei. The position of the posterior coracoid fenestra is thus filled with a thin layer of bone as it was observed in Scandensia (Evans and Barbadillo 1998), which is quite susceptible to breakage or was still incompletely ossified, given the specimen immaturity.

The scapulae are preserved on their proximalmost portion, at the junction with the coracoid and the glenoid facet, which is observable in dorsal view. The anterior margins of both scapulae are slightly concave, delineating the posterodorsal border of the scapulocoracoid fenestrae. Anterodistally, on the right scapula, the origin of the scapular ray is visible, but the acromion process and/or the supraescapula articular surface are not preserved.

The interclavicle is the ventralmost element preserved and can be seen on its anterior portion. Anteriorly, it possesses a prominent anterior process and a short lateral one, preserved on the right side only. Posteriorly, the shaft is a relatively narrow element, until it disappears beneath the sternal plate, and it is not visible at the sternal fontanelle as it would be expected. Both clavicles are present, with the left one better preserved, which extends posterolaterally in a smooth angle from its contact with the anterior process of the interclavicle throughout most of its way before connection with the scapula. The right clavicle has preserved only its proximal region, but its connection with the anterior interclavicle process is more exposed, revealing its angulated structure. The clavicles are anteroposteriorly flattened at their distal end, they have a circular cross section throughout most of their length and become flattened again at their proximal contact with the interclavicle, at their angulated ends. 


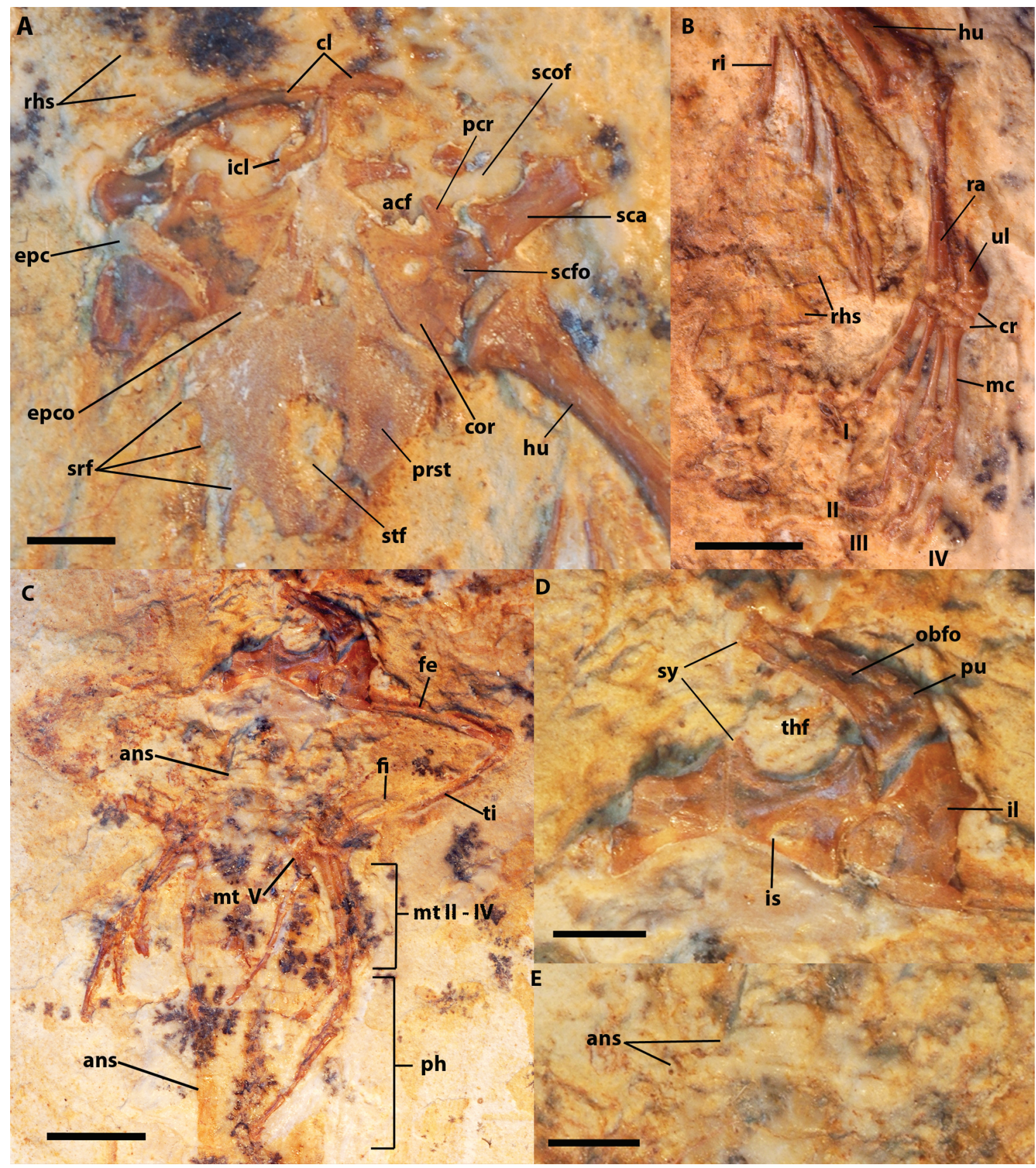

Fig 3. A, pectoral girdle of MPSC-V 010 in dorsal view. Scale $=2 \mathrm{~mm}$. B, Right forearm and manus in dorsolateral view. Larger rhomboid scales disposed in serial longitudinal and transverse rows. Scale $=3 \mathrm{~mm}$. C, Posterior trunk and anterior caudal region of MPSC-V 010 in dorsal view. Scale $=15 \mathrm{~mm}$. D, The pelvic region, mostly preserved in its right half. Scale $=2 \mathrm{~mm}$. E, Enlargement of the anterior annulated caudal scales. Scale $=2 \mathrm{~mm}$. 


\section{FORELIMBS}

Both limbs are in retracted position and stand close to the body, with the elements in the right limb better preserved than the ones in the left. The right humerus is in posterodorsal view and exhibits a low humeral condyle for the articulation with the glenoid cavity. It has a well-developed deltopectoral crest descending from its proximoanterior face towards the shaft. Between the humeral condyle and the glenoid cavity there is an irregular mass of cartilage preserved indicating the specimen was still in its growing phase. Distally, the right humerus suffers an almost $90^{\circ}$ rotation on its own axis, making the distal condyles visible in posterior aspect (Fig. 3b). The entepicondyle lies posteroventrally and is bigger than the ectepicondyle, which is dorsal and slightly more proximal on the shaft. No clear ectepicondylar foramen is visible, but we cannot rule out the possibility of its presence on $T$. pontei based solely on this angle of view and from a single humerus. Between these two condyles lie the ulnar and radial condyles, which can be seen as a two small bulbous structures in posterior view.

The right forearm suffered lateral rotation, with the ulna impression lying dorsally on the radius and its distal end laterally to it. Among the mesopodials, the ulnares are flattened proximodistally in tight association with the ulnar distal articulatory surface. The radiale is visible on the right wrist, below the radial distal facet, and no distinct centrale or intermedium can be observed. All the five distal carpals are preserved and are similar sized to each other. The first three digits of the right hand are almost complete, with a phalangeal formula of 2-3-3, but the formula for the fourth and fifth digits cannot be determined with certainty on either hands.

\section{PELVIC GIRDLE}

The three constituent paired elements of this structure are better preserved on their right side, are not completely fused and, as with the pectoral girdle, lie in articulation with the limbs (Fig. 3c). The ilium is collapsed laterally and has only its anteriormost region preserved, hiding most of its morphological structures, but still enabling a view of its acetabular concavity and a small anterior process. The ischia are wider than long and meet medially, forming a symphysial joint and two short anterior projections for, presumably, articulation with the not preserved proischium (Fig. 3d). Posteriorly on the same joint there is no articulatory face for the hypoischium, indicating that this was not present. The left ischium is broken at its lateral end, but on the right one it is clear that it has a thick ischiadic neck which runs from the acetabular contribution of the ischium down to its posteromedial extremity. Posterolaterally there is a concavity on this same element, which is limited medially by the process that leads to the ischiadic tuberosity. As with the coracoids, the right ischium possesses an aperture on its posterior portion, which is absent on its left counterpart. It has irregular margins and is partially filled with a thin bone layer, indicating that this is not a true fenestra. Therefore, this might be due to breakage or an ontogenetic bias as well, indicating a delay on the ossification of the plate forming this portion of the ischium in relation to the other pelvic elements.

The right pubis is a slender, elongate and slightly curving element with a robust posterior rim and concavity that form the anterior face of the thyroid fenestra (Fig. 3d). The obturator foramen is ellipsoidal and perforates the pubic shaft close to its acetabular end. The pubis lacks the processus lateralis, and the pubic tubercle is not clearly distinct as well and might have been absent here. Therefore, the pubic apron between the tubercle and the ventromedial process leading to the symphysial joint is also absent. The symphysis between the pubes is very short anteroposteriorly and its median cartilage is still preserved. 


\section{HIND LIMBS}

The hind limbs are not as well preserved as the anterior ones, being only visible for most of their extension by low relief impressions on the matrix (Fig. 3c). However, these impressions made it possible to measure some of their elements, among other observations. The posterior limbs are much longer than the anterior ones - humeroulnar length being only $64.5 \%$ of the total femorotibial length.

The femora are badly preserved, with only the right one having bony structures besides the impressions on the matrix. The right femur is seen in posteroventral view and is curved dorsally, even though at a quite low angle. Proximally, the femoral condyle is seen in articulation with the pelvic girdle. The shaft is elongate and terminates at the condylar area of articulation with the tibia and fibula. However, it is not possible to distinguish the lateral and medial condyles from this angle.

The tibia and fibula of both posterior limbs lack clearly distinguishing features. However, the right foot has the first digits preserved laterally, indicating that the lateral epipodial above it is the tibia and the remaining one the fibula. They are equal in length with each other and with the femur - tibial length being $98.9 \%$ of the femoral length.

The astragalum and calcaneum impressions are seen, but the elements themselves are not preserved and we cannot know for sure if they were already fully ossified or fused to each other. At the right foot, which is better preserved, the fifth digit is preserved in articulating position with the impression of the fifth metatarsal. The distal tarsals, however, were not preserved well enough for their identification. The second to fourth metatarsals are also in natural position, well elongated and subequal in length (Fig. 3c). The phalanges were displaced distally and many of them are missing or overlap each other, making it difficult to infer their topological homology. Still, it is clear that at least two of its digits were extremely elongated.
This is supported by the close proximity between the proximal end of the preserved phalanges and the distal end of the metatarsals.

\section{SOFT TISSUE}

MPSC-V 010 has scales preserved on the cervical region, trunk and tail. On the neck, there are very small rhomboid scales adjacent to each other without overlapping or particular pattern of distribution (Fig. 3a). The left clavicle, which is present at the posterolateral region of this patch of tissue, lies dorsally to it, indicating these are ventral scales. On the trunk region there are large rhomboidal scales ventral to the right ribs, thus also representing the ventral integument. They are arranged in transverse and longitudinal rows, being more visible at the abdominal region close to the right forearm (Fig. 3b). The tail possesses large rectangular scales arranged in transverse rows (annulated scales), from the base of the tail to its posterior tip. These are preserved under the bony elements of the right foot, indicating that these are also ventral scales (Fig. 3e)

\section{DISCUSSION}

Despite being originally described as an adult specimen, the holotype of Tijubina pontei contains a set of characters that are associated with skeletally immature lizards. It includes: incompletely calcified epiphysial regions between the humeral condyles and the glenoid cavities; a wide open sternal fontanelle (Russell and Bauer 2008); scapulae and coracoids unfused (Maisano 2002, Evans et al. 2005); and pelvic girdle elements unfused (Evans and Yabumoto 1998, Maisano 2002). Nevertheless, the ossification of the carpal elements on the forelimbs and the complete ossification of the fifth hand digit indicate that this is not a recently hatched specimen, as observed in recent lizard species and other fossil reptiles (Rieppel 1994, Caldwell 1997, Motani 1999). 
The holotype of $T$. pontei differs from $O$. brasiliensis by not having the strong posterodorsal (coronoid) ramus of the dentary, which brackets the surangular below it and above the angular (Evans and Yabumoto 1998). In fact, in MPSC-V 010 the dentary extends posteriorly in lateral view without distinct posterodorsal or posteroventral processes, having only an irregular dorso-ventral suture separating it from the surangular. This character also places it basally within the Evansauria clade of Conrad (2008). Another difference with $O$. brasiliensis is the relative length between the tibia and fibula against the femur (see the "Hind limbs" section above). In O. brasiliensis the epipodials are $80 \%$ of the femoral length, whereas in T. pontei both are almost equally sized (98.9\%). Therefore, both $T$. pontei and $O$. brasiliensis indeed represent different valid species from the same locality and horizon.

Despite preserving numerous skeletal elements, T. pontei lacks most of its cranial bones, which would be especially useful for a phylogenetic analysis and its placement within the squamates. Still, it possesses some diagnosable features at a higher hierarchical level: its anteroventral border of the orbit formed by the jugal and also an anterior (primary) coracoid emargination are diagnostic character states for Squamata under Estes et al. (1988); the hooked fifth metatarsal and a narrow contact of the pubes at symphisis are sinapomorphies for the squamates under Gauthier et al. (1988). Also, the wide open thyroid fenestra, totally separating the ischium from the pubis and a pterygoid flange anterolaterally directed are both squamate synapomorphies under de Braga and Rieppel (1997). These go against the statement of Martill and Frey (1998, p. 79 - 80) that this material belongs to a Rhyncocephalia.

The cruciform interclavicle with a distinct anterior process, a relatively extensive and narrow symphysial process of the pubis, along with angulated clavicles, place Tijubina within the Scleroglossa (Estes et al. 1988, Lee 1998, Conrad 2008). The absence of distinct posterior processes on the dentary, as said above, with the lack of expansions on its anterior presacral ribs, place $T$. pontei within the Evansauria (sensu Conrad 2008). This is a newly erected clade that includes the Autarchoglossa and basal scleroglossans such as the Bainguidae and the species Tepexisaurus tepexii Reynoso \& Callison 2000 and Parmeosaurus scutatus Gao \& Norell, 2000. Within it, T. pontei seems to occupy a rather basal position. It does not have an angulated ("L" shaped) jugal or a visible posteroventral process, both synapomorphies of Autarchoglossa (sensu Conrad 2008). In another major analysis of the Squamata Lee (1998) did not recover a monophyletic Autarchoglossa. However, Lee's (1998) clade C is roughtly equivalent to the Autarchoglossa (sensu Estes et al. 1988), as it includes: lacertids, teiids, gymnophtalmids, scincids, cordylids and anguimorphs. Based on this work, T. pontei would also be a basal scleroglossan, falling outside clade $\mathrm{C}$, as it lacks a large splenial and fusion among the articular, prearticular and surangular. Unfortunately, other characters directly comparable with Estes et al. (1988) apomorphies for the Autarchoglossa were not preserved, such as the upper temporal bar elements. Nevertheless, the available evidence from Tijubina's holotype and other phylogenetic analysis convergently place it outside the Autarchoglossa.

Originally, T. pontei was classified as a teiid despite lacking autarchoglossan sinapomorphies. Furthermore, the absence of a posterior coracoid emargination confirms that it does not belong to the Teiioidea (sensu Estes et al. 1988, Lee 1998, Conrad 2008). Therefore, it confirms that T. pontei is a basal Scleroglossa and not a teiid as originally stated.

\section{CONCLUSION}

The holotype of Tijubina pontei has been extensively redescribed and includes, for the first time, the diagnostic features needed for the proper delimitation of this species from other Cretaceous 
lizards, especially from Olindalacerta brasiliensis. The former was described posteriorly to Tijubina, and a comparison between both species was not provided until now and was not possible via the available literature. The comparison provided herein confirms the validity of both species.

Tijubina pontei seems to occupy a basal position among scleroglossans, outside the Autarchoglossa and slightly more derived than Olindalacerta (see Evans and Yabumoto 1998). This goes against its initial placement within the teiids (Bonfim-Júnior and Marques 1997) and from its later assignment as a basal squamate - the sister group of Iguania + Scleroglossa, being only more derived than Huehuecuetzpalli (Bonfim-Júnior and Avilla 2002). Therefore, a phylogenetic analysis that includes the new information provided in this work would be important for a better establishment of the systematic position of Tijubina pontei. Further descriptions of new materials will certainly contribute to further enlightment on the systematics of these and other South American Mesozoic lizards.

\section{ACKNOWLEDGMENTS}

I would like to thank the great help provided to me by Dr. Álamo Feitosa (Universidade Regional do Cariri - URCA) and Msc. João Kerensky (Universidade Federal do Ceará - UFC), who also constributed with two photographs in figure 3, during my research period at the Museu de Paleontologia de Santana do Cariri and at Crato. I am also greatfull for the corrections and improvements suggested by three anonymous reviewers. This project was partially funded by the Conselho Nacional de Desenvolvimento Científico e Tecnológico (CNPq).

\section{RESUMO}

O registro de lagartos do Mesozóico de Gondwana é extremamente limitado. Dentre as poucas espécies descritas para esta região está Tijubina pontei, um lagarto do Cretáceo Inferior da Formação Crato (Aptiano superior) do nordeste do Brasil. A sua descrição é muito breve e não contém a maioria dos seus caracteres diagnósticos ou uma clara delimitação das outras espécies de lagartos. Neste trabalho, uma redescrição completa do holótipo, é provida. É demonstrado que $T$. pontei é espécie válida, e uma nova diagnose é provida com referência à Olindalacerta brasiliensis, uma espécie contemporânea da Formação Crato. Ele não possui os processos posteroventral e posterodorsal do dentário; o comprimento tibilar/fibular é relativamente igual ao comprimento do fêmur e os seus dentes posteriores no dentário são robustos, de base cilindrica, sem ornamentações e sem cúspides. Embora a posição sistemática de $T$. pontei ainda necessite de maiores esclarecimentos, estudos preliminares indicam que este é um lagarto basal dentre os Squamata, de modo similar a $O$. brasiliensis.

Palavras-chave: Brasil, Formação Crato, lagarto fóssil, Cretáceo Inferior, Tijubina pontei.

\section{REFERENCES}

BÁez AM, Moura GJB And Gómez RO. 2009. Anurans from the Lower Cretaceous Crato Formation of northeastern Brazil: implications for the early divergence of neobatrachians. Cretaceous Res 30: 829-846.

BONFIM-JÚNIOR FC AND AVILLA LDS. 2002. Phylogenetic position of Tijubina pontei Bonfim \& Marques, 1997 (Lepidosauria, Squamata), a basal lizard from the Santana Formation, Lower Cretaceous of Brazil. J Vert Paleont 22: 37A-38A.

BONFIM-JÚNIOR FC AND MARQUES RB. 1997. Um novo lagarto do Cretáceo do Brasil. An Inst Geoc UFRJ 20: 233-240.

Broschinski A AND Sigogneau-Russell D. 1996. Remarkable lizard remains from the lower Cretaceous of Anoual (Morocco). Ann Paleont 82: 147-175.

CALDWELl MW. 1997. Modified perichondral ossification and the evolution of paddle-like limbs in ichthyosaurs and plesiosaurs. J Vert Paleont 17: 534-547.

CAMPOS DA AND KELLNER AWA. 1997. Short note on the first occurrence of Tapejaridae in the Crato Member (Aptian), Santana Formation, Araripe Basin, northeast Brazil. An Acad Bras Cienc 69: 83-87.

CAMPOS DRB. 1986. Primeiro registro fóssil de Scorpionoidea na chapada do Araripe (Cretáceo Inferior), Brasil. An Acad Bras Cienc 58: 135-137.

CONRAD JL. 2008. Phylogeny and Systematics of Squamata (Reptilia) based on morphology. Bull Am Mus Nat Hist 310: 1-182. 
DATTA PM AND RAY S. 2006. Earliest lizard from the Late Triassic (Carnian) of China. J Vert Paleont 26: 795-800.

De Braga M AND Rieppel O. 1997. Reptile phylogeny and the interrelationships of turtles. Zoo J Linn Soc 120: $281-354$

Estes R, De QueIroz ET AND GAUthIER JA. 1988. Phylogenetic relationships within Squamata. In: ESTES R AND PREGILL G (Eds), Phylogenetic relationships within the lizard families: Stanford University Press, Stanford, USA, p. 119-281.

Estes R AND PRICE LI. 1973. Iguanid lizard from the Upper Cretaceous of Brazil. Science 180: 748-751.

EVANS SE. 2003. At the feet of the dinosaurs: the early history and radiation of lizards. Biol Rev 78: 513-551.

EVANS SE AND BARBADILLO LJ. 1998. An unusual lizard (Reptilia: Squamata) from the Early Cretaceous of Las Hoyas, Spain. Zoo J Linn Soc 124: 233-265.

Evans SE, Prasad GVR and Manhas BK. 2002. Fossil lizards from the Jurassic Kota Formation of India. J Vert Paleont 22: 299-312.

Evans SE, WANG Y AND LI C. 2005. The early Cretaceous lizard genus Yabeinosaurus from China: resolving an enigma. J Syst Palaeont 3: 319-335.

Evans SE AND Yabumoto K. 1998. A lizard from the Early Cretaceous Crato Formation, Araripe Basin, Brazil. N Jahr Geol Paläont Mon 6: 349-364.

Frey E AND Martill DM. 1994. A new pterosaur from the Crato Formation (Lower Cretaceous, Aptian) of Brazil. N Jahr Geol Paläont Abh 194: 379-412.

GaO K AND Norell MA. 2000. Taxonomic composition and systematics of Late Cretaceous lizard assemblages from Ukhaa Tolgod and adjacent localities, Mongolian Gobi Desert. Bull Am Mus Nat Hist 249: 1-118.

GAuthier JA, Estes R AND DE QueIroz ET. 1988. A phylogenetic analysis of Lepidosauromorpha. In: ESTES R AND PREGILL G (Eds), Phylogenetic relationships within the lizard families: Stanford University Press, Stanford, USA, p. 15-98.

Kellner AWA. 1998. Panorama e perspectiva do estudo de répteis fósseis no Brasil. An Acad Bras Cienc 70: 647-676.

KELLNER AWA AND CAMPOS DDA. 1999. Vertebrate paleontology in Brazil - a review. Episodes 22: 238-251.

Kellner AWA, Maisey JG AND CAMPos DA. 1994. Fossil down feather from the Lower Cretaceous of Brazil. Palaeontology 37: 489-492.

Krause DW, Evans SE AND Gao KQ. 2003. First definitive record of Mesozoic lizards from Madagascar. J Vert Paleont 23: $842-856$
LEAL MEC AND BRITO PM. 2006. Anura do Cretáceo Inferior da Bacia do Araripe, Nordeste do Brasil. In: GALLO V et al. (Eds), Paleontologia de vertebrados - grandes temas e contribuições científicas: Interciência, Rio de Janeiro, Brasil, p. 145-152.

LEE MSY. 1998. Convergent evolution and character correlation in burrowing reptiles: towards a resolution of squamate relationships. Biol J Linn Soc 65: 369-453.

MAISANO JA. 2002. Terminal fusions of skeletal elements as indicators of maturity in squamates. J Vert Paleont 22: $268-275$.

MAISEY JG. 1991. Santana fossils; an illustrated atlas: T. F. H. Publications, Neptune, NJ, USA, 459 p.

MAISEY JG. 1993. Tectonics, the Santana lagerstätten, and the implications for late Gondwanan biogeography. In: GOLDBLATT P (Ed), Biological relationships between Africa and South America: Yale University Press, New Haven, USA, p. 435-454.

MARTILL DM, BEChLY G AND LOVERIDGE RF. 2007. The Crato fossil beds of Brazil: Cambridge University Press, Cambridge, UK, $625 \mathrm{p}$.

MARTILL DM AND FREY E. 1998. A new pterosaur lagerstatte in N. E. Brazil (Crato Formation; Aptian, Lower Cretaceous): Preliminary Observations. Oryctos 1: 79-85.

Martins-Neto RG. 1987. Primeiro registro de decápode da Formação Santana, bacia do Araripe (Cretáceo Inferior), Brasil. Cienc Cult 39: 406-410.

MARTINS-NeTO RG. 2002. The Santana Formation paleoentomofauna reviewed. Part I - Neuropteroidea (Neuroptera and Raphidioptera): systematic and phylogeny, with description of new taxa. Acta Geol Leop 55: 35-66.

Motani R. 1999. On the evolution and homology of ichthyosaurian forefins. J Vert Paleont 19: 42-49.

NAVA WR AND MARTINELLI AG. 2011. A new squamate lizard from the Upper Cretaceous Adamantina Formation (Bauru Group), São Paulo State, Brazil. An Acad Bras Cienc 83: 291-299.

Neumann VH AND CABRERA L. 1999. Una nueva propuesta estratigráfica para la tectonosecuencia post-rifte de la cuenca de Araripe, noreste de Brasil. In: Simpósio Sobre o Cretáceo do Brasil, 5, Rio Claro. Boletim do $5^{\circ}$ Simpósio Sobre o Cretáceo do Brasil. UNESP, Rio Claro, p. 279-285.

NeUmanN VH AND CABRERA L. 2002. Características hidrogeológicas gerais, mudanças de salinidade e caráter endorréico do sistema lacustre cretáceo do Araripe, NE Brasil. Rev Geol 15: 43-54.

OliveIra G AND Kellner AWA. 2007. A new side-necked turtle (Pleurodira, Pelomedusoides) from the Santana Formation (Early Cretaceous), Araripe Basin, Northeastern Brazil. Zootaxa 1425: 53-61. 
Reynoso VH and Callison G. 2000. A new scincomorph lizard from the Early Cretaceous of Puebla, Mexico. Zoo J Linn Soc 130: 183-212.

RICHTER A. 1994. Lacertilia aus der Unteren Kreide von Uña und Galve (Spanien) und Anoual (Marokko). Berl Geowiss Abh E 14: 1-147.

Rieppel O. 1994. Studies on skeleton formation in reptiles. Patterns of ossification in the skeleton of Lacerta agilis exigua Eichwald (Reptilia, Squamata). J Herp 28: 145-153.

RUSSELl AP AND BAUER AM. 2008. The appendicular locomotor apparatus of Sphenodon and normal-limbed squamates. In: GANS C ET AL. (Eds), Biology of the Reptilia - The Skull and Appendicular Locomotor Apparatus of Lepidosauria, n. 21. Soc Stud Amph Rept, Ithaca, NY, USA, p. 1-465.

SANTOS MFA, Mermudes JRM AND FonseCA VMD. 2011. A specimen of Curculioninae (Curculionidae, Coleoptera) from the Lower Cretaceous, Araripe Basin, north-eastern Brazil. Paleontology 54: 807-814.
SAYão JM, SARAIVA AAF AND UEJIMA AMK. 2011. New evidence of feathers in the Crato Formation supporting a reappraisal on the presence of Aves. An Acad Bras Cienc 83: 197-210.

VALENÇA LMM, NeUMANN VH AND MABESOONE JM. 2003. An overview on Callovian-Cenomanian intracratonic basins of northeast Brazil: onshore stratrigraphic record of the opening of the southern Atlantic. Geol Acta 1: 261-275.

VIANA MSS AND NEUMANN VHL. 2002. Membro Crato da Formação Santana, Chapada do Araripe, CE Riquíssimo registro de fauna e flora do Cretáceo. In: SCHOBBENHAUS C ET AL. (Eds), Sítios Geológicos e Paleontológicos do Brasil: DNPM/CPRM/SIGEP, Brasília, Brasil, p. 113-120. 